\title{
ANÁLISE DO DISCURSO NAS REDES SOCIAIS: A INFLUÊNCIA DE POSTAGENS NAS DECISÕES JUDICIAIS
}

Rogério do Amaral, Leticia Rodrigues Biassoti

Universidade do Oeste Paulista - UNOESTE, Curso de Comunicação Social, Presidente Prudente, SP. E-mail: rgamaral@unoeste.br

\section{RESUMO}

O objetivo do presente artigo é compreender como o discurso produzido nas redes sociais é inserido no universo jurídico como prova em decisões judiciais para, então, discutir como o universo virtual não pode mais ser considerado como um local a parte de nossa sociedade, já que o discurso ali produzido reflete na vida dos usuários. A metodologia empregada é a análise linguística do discurso de um usuário de rede social em diversos casos de ódio, situações em que o réu foi condenado repetidas vezes a partir da aceitabilidade do seu discurso virtual como prova judicial. Como resultado, nota-se que o ambiente virtual é também parte de nossa sociedade e os ataques de ódio crescentes nesse espaço nos últimos anos estão sim ao alcance de nossa legislação, por isso, cresce a cada dia as sentenças condenando indivíduos por causa das postagens feitas nas diferentes redes sociais.

Palavras-chave: Análise do Discurso, Redes Sociais, Decisões Judiciais.

\section{SPEECH ANALYSIS IN SOCIAL NETWORKS: THE INFLUENCE OF POSTS IN JUDICIAL DECISIONS}

\begin{abstract}
The object of this article is to understand how the speech produced in social networks is inserted in the legal universe as evidence in judicial decisions to then discuss how the virtual universe cannot be considered as a local apart of our society, since the discourse produced there reflects in the life of the users. The methodology used is the linguistic analysis of speech of a social network user in various cases of hate, situations in which the defendant has been repeatedly condemned from the acceptability of his virtual speech as judicial evidence. As a result, is notable that the virtual ambient is also part of our society and the increasing hate attacks is this space in the last years are within the reach of our legislation, so, grows every day the sentences condemning individuals because of the posts made in different social networks.
\end{abstract}

Keywords: Speech Analysis, Social networks, Judicial Decisions.

\section{INTRODUÇÃO}

Este artigo se constrói a partir de três elementos: o discurso, as redes sociais e as decisões judiciais. Tal junção se deve ao fato do discurso produzido nas redes sociais, cada vez mais ser utilizado como prova em decisões judiciais. Essa repetida ocorrência nos faz refletir sobre o fato de que cada vez mais as redes sociais se inserem em nossas vidas, porém, agora o usuário é cobrado e responsabilizado pelo comportamento ali assumido, ou seja, o discurso no mundo virtual já é reconhecido como uma atividade social, e isso faz com que todas as postagens em redes sociais sejam alvo da aplicação da legislação brasileira, em diferentes situações.

No que se refere às relações interpessoais, desde meados da década de 1990, a sociedade passou a conviver com um novo mecanismo de diálogo que na atualidade se consolida como ferramenta preponderante no que tange à comunicação entre os sujeitos, com distintos objetivos. Essa ferramenta é a rede social, lugar em que "cada indivíduo tem sua função e identidade cultural. Sua relação com outros indivíduos vai formando um todo coeso que representa a rede." (TOMAÉL; ALCARÁ; CHIARA, 2005, p. 93). Nesse ambiente das redes 
sociais, as comunidades virtuais pautam as relações sociais, pois os usuários podem acompanhar a vida cotidiana de seus contatos presenciais mesmo à distância, originando uma rede de vínculos íntimos e não íntimos, que aproxima os usuários da intimidade e da vida privada do outro (KAUFMAN, 2010, p. 10).

Nesse sentido, as redes sociais podem ser compreendidas como "[...] sofisticadas e complexas 'estradas' que permitem o compartilhamento pelos indivíduos, com velocidade e confiabilidade, de enormes fluxos de informações e, mais relevante, em 'tempo real' independente da distância [...]." (KAUFMAN, 2010 , p. 24). Nas redes sociais, o primeiro elemento de uma rede social são os atores, estes representados pelas pessoas que fazem parte do sistema o qual se analisa, moldando as estruturas, por meio da interação (RECUERO, 2009, p.25). Dessa forma, as informações são constantemente compartilhadas, pois os indivíduos querem divulgar 0 que sabem (TOMAÉL; MARTELETO, 2006, p.76), o que gera um importante fator quanto à tomada de decisões dos internautas, que lidam a todo instante com opiniões, experiências, em um cenário de confiança mútua. (KAUFMAN, 2010, p. 127).

Assim, os discursos produzidos na rede social não podem mais ser considerados como algo alheio à nossa realidade social, pois o que ali se desenvolve tem relação estrita com nossos atos cotidianos e gera consequências na vida de cada um dos usuários e, por conseguinte, interlocutores virtuais. Portanto, já não existe mais a possibilidade de se separar os atos do mundo virtual de nossas ações sociais diárias. Por isso, cada vez mais se torna relevante compreender e discutir o discurso produzido nas redes sociais, com o propósito de entender de que maneira tal ocorrência tem impactado nossa vida social.

Quanto à Análise do Discurso (AD), segundo Gregolin (1995), ao analisar o discurso, inegavelmente questões surgem no que tange ao relacionamento da situação que o gerou, a língua que será estudada pela linguística e a sociedade, apreciada pela história e pela ideologia. "O discurso é um suporte abstrato que sustenta os vários textos (concretos) que circulam em uma sociedade [...]. Através da Análise do Discurso é possível realizarmos uma análise interna (o que este texto diz?, como ele diz?) e uma análise externa (por que este texto diz o que ele diz?)." (GREGOLIN, 1995, p. 17).

Com a AD, a língua se transforma, dessa forma, elementos considerados opostos podem caminhar juntos, como o erro e o acerto, pois “[...] A língua do analista de discurso é outra. É a língua da ordem material, da opacidade, da possibilidade do equívoco como fato estruturante, da marca da historicidade inscrita na língua. É a língua da indefinição do direito e avesso, do dentro e fora, da presença e ausência." (FERREIRA, 2003, p. 42). Por isso, esse estudo analisa o resultado jurídico do discurso nas redes sociais, visando compreender como essa historicidade está presente no discurso produzido nas redes sociais e de que maneira esse fato interfere em nossas vidas e, nesse caso, em decisões judiciais.

Sobre as decisões judiciais, Nojiri (2017) afirma que existem duas possibilidades para se compreender o significado de "decisão judicial". A primeira, analisada em sentido estrito, é o ato que encerra o processo judicial, e a segunda em sentido lato, abrange as escolhas realizadas durante a tramitação processual, isto é, sem o propósito de finalizá-lo. "A decisão judicial diferencia-se dos demais tipos de decisão por um fator muito preciso, ela é produzida por uma autoridade especialmente designada para o exercício dessa função qual seja o juiz [...]." (MONTEIRO, 2007, p. 6114)

Nesse sentido, a discussão jurídica, em cada caso, regularmente, consiste no esclarecimento dos fatos trazidos em juízo, onde as partes devem comprová-los para que sejam utilizados como provas, deste modo, a prova tem o propósito de demonstrar a verdade da afirmação exposta (PAGANELLI; SIMÕES, 2012). A experiência indica, todavia, que não é aconselhável a total liberdade na admissibilidade dos meios de prova, ora porque não se fundam em bases científicas suficientemente sólidas para justificar seu acolhimento em juízo [...]; ora porque dariam perigoso ensejo a manipulações ou fraudes [...]. (CINTRA; GRINOVER; DINAMARCO, 2015, p. 428). Dessa forma, em um mundo cada vez mais moderno "a evolução social trazida pela Informática, fez com que o Direito necessitasse de novos instrumentos para disciplinar as relações entre o homem e a tecnologia, visando preservar o convívio, a harmonia e a paz social [...]. Disto, surge o Direito Digital." (GIRARDELLO, 2017) e também os novos 
modelos de produção de provas, em destaque, os eletrônicos.

Nesse contexto, 0 presente artigo apresenta o objetivo de compreender como o discurso produzido nas redes sociais é inserido no universo jurídico como prova em decisões judiciais para, então, discutir que o universo virtual não pode mais ser considerado como um local a parte de nossa sociedade, já que o discurso ali produzido reflete na vida dos usuários.

\section{METODOLOGIA}

A partir do levantamento de dois artigos jornalísticos publicados na internet, o primeiro na página da revista Isto É e o segundo na página do site $G 1$, este artigo desenvolveu uma análise linguística sobre o discurso de um réu condenado, repetidas vezes, devido às suas publicações em diferentes redes sociais. Portanto, aplica-se nesse artigo um estudo sobre o discurso produzido nas redes sociais para vislumbrar de que forma tal discurso enquadra-se como prova na legislação brasileira e leva essa repetida prática a configurar-se como prova em sentença judicial.

Segundo Manhães (2009), a interpretação do sentido de um dado discurso deve considerar que a significação é construída no interior da fala de determinado sujeito, nesse caso, o réu citado. $O$ autor ainda afirma que o discurso é apropriação da linguagem por um emissor, que age de forma ativa, constituindo o chamado sujeito da ação social. Portanto, o discurso, independente do lugar em que é produzido, configura-se como ação social, por isso, analisar essa produção discursiva das redes sociais se torna relevante para entendermos a comunicação e um ambiente tão presente em nosso cotidiano.

\section{RESULTADOS}

O caso selecionado para análise deste artigo se refere a uma prisão preventiva realizada pela Polícia Federal na Operação Bravata, que visa combater os crimes praticados na internet, dentre os quais estão o racismo, a ameaça e a incitação à prática de terrorismo que ocorreu em Curitiba na data de 10 de maio de 2018. O mandado judicial fora expedido por Marcelo Josegrei, da 14a Vara Federal, o alvo foi Marcelo Mello, já reincidente nas mesmas acusações. Em 2005, por meio da rede social Orkut, publicou que negros eram "burros, subdesenvolvidos, incapazes, ladrões". Na ocasião, foi absolvido alegando insanidade.

Já em 2009, foi o primeiro condenado na justiça brasileira por crime de racismo na internet, punido com um ano e dois meses de prisão por se posicionar de maneira preconceituosa contra as cotas na instituição de Letras-Japonês da Universidade de Brasília onde estudava na época. No ano seguinte, em um blog, escreveu "as estudantes são 'vadias bissexuais imundas' e 'degeneradas', os militantes do movimento negro são 'cotistas de bosta', e os gays são 'maconheiros cheios de AIDS.'" Havia ainda o "guia do estupro", com instruções testadas na Universidade Estadual Paulista (UNESP), em Araraquara, interior de São Paulo.

Em 2012, tinha um site com conteúdo parecido ao investigado atualmente, quando foi preso pela Polícia Federal durante a Operação Intolerância, condenado a seis anos e sete meses em regime semiaberto. Em 2013, assim que ficou livre da prisão preventiva escreveu um e-mail fazendo ameaças para a professora Lola Aronovich, da Universidade Federal do Ceará, autora de um blog feminista que postava denúncias contra Mello. "Acompanho o fórum dele e passei prints de postagens para a divisão de Direitos Humanos da Polícia Federal", disse a docente.

\section{DISCUSSÃO}

A partir das situações acima, observa-se que Mello possui discurso de ódio devido à historicidade. Há uma repetição de postagens contra as minorias, o que nos permite depreender a reprodução de um discurso da massa, que em nosso país se produz como forma de ataque contra negros, homossexuais e também as mulheres. Mello foi apenas mais enfático quanto ao ódio manifesto por seu discurso nas redes sociais, local que ele escolheu para dar visibilidade à sua visão preconceituosa contra essa minoria já citada. O discurso de Mello também nos permite depreender uma característica comum do discurso virtual, o posicionamento subjetivo, sem nenhuma base de sustentação. Assim, ataca os negros que alcançaram o direito de ingressar em universidades públicas devido às cotas ou julga àquilo que psicologicamente acredita não ser certo, como a orientação sexual diversificada, posicionamento que nos permite verificar um discurso fruto do machismo existente em nossa sociedade, em que o homem é o mais forte e o 
provedor da construção de uma família, portanto, a linguagem reflete toda essa bagagem, que é a forma pelo qual se externa ideologias e pensamentos.

Diante deste fato, a relação que se pode estabelecer entre a $A D$ e as manifestações virtuais, é que elas variam de acordo com quem as emite, igualmente aos pilares que fundamentam a teoria da Análise do Discurso que recebem influência de grandes áreas. Desse modo, a compreensão quanto às ações com esse caráter tornam-se mais fáceis de interpretar quando profundamente observadas, sem se limitar a pura e simples linguagem, o que não significa dizer que é justificável, pois toda conduta que causar ou for capaz de causar um dano, deve ser devidamente punida, a fim de restaurar a ordem e a paz social.

"Por ocorrem em ambientes virtuais, [as publicações] atingem um indefinido número de pessoas, tornado imensurável a extensão dos danos. Ofendem a dignidade humana, igualmente reconhecida como direito inalienável e protegida por garantias constitucionais", comentou Josegrei. Evidente que as plataformas digitais são meios que fornecem mais autonomia aos indivíduos em uma sociedade democrática, todavia, a definição do que vem a ser a liberdade de expressão não pode ser esquecida, bem como, os limites inerentes a esse princípio, uma vez que jamais deve ser absoluto.

\section{CONCLUSÃO}

Portanto, a legislação brasileira compreende 0 universo virtual como uma extensão de nosso mundo social, pois quem ali discursa é membro de nossa sociedade, dessa forma, os atos de ataque ali praticados se sujeitam ao rigor da lei, da mesma forma, que atos semelhantes praticados em outros ambientes sociais, como as escolas, por exemplo.

Em pleno século $X X I$, os indivíduos precisam assumir a responsabilidade pelos atos praticados, assim nosso sistema judiciário acerta em punir sujeitos que se escondem atrás de um login em páginas da internet para atacar membros das minorias sociais, principalmente, em um momento em que tais agressões são cada vez mais marcadas pelo ódio contra aqueles que defendem ideologias contrárias às defendidas por esses usuários.

\section{REFERÊNCIAS}

CINTRA, A. C. A.; GRINOVER, A. P.; DINAMARCO, C. R. Teoria Geral do Processo. 31. ed. rev. ampl. São Paulo: Malheiros, 2015.

FERREIRA, M. C. L. O quadro atual da análise de discurso no Brasil. Espaços de Circulação da Linguagem, Santa Maria, n.27, p.39-46, dez., $2003 . \quad$ Disponível em: <https://periodicos.ufsm.br/letras/article/view/1 1896/7318>. Acesso em: 06 jan. 2018.

GIRARDELLO, D. P. O que é Direito Digital? Conceito de Direito Digital e sua abrangência. $2017 . \quad$ Disponível em: <https://diogoprestes.jusbrasil.com.br/ artigos/252818928/o-que-e-direito-digital>. Acesso em: 17 jan. 2018.

GREGOLIN, M. D. R. V. A análise do discurso: Conceitos e aplicações. Alfa, São Paulo, n.39, p.13-21, $1995 . \quad$ Disponível em: <http://seer.fclar.unesp.br/alfa/article/viewFile/3 967/3642>. Acesso em: 15 jan. 2018

ISTOÉ Independente. "O criminoso da internet". Disponível em: <https://istoe.com.br/434177_O+CRIMINOSO+D A+INTERNET/>. Acesso em: 15 jul. 2018.

KAUFMAN, D. Processo de tomada de decisões no ciberespaço - o papel das redes sociais no jogo das escolhas individuais. 2010. Dissertação (Mestrado em Comunicação) Pontifícia Universidade Católica de São Paulo, São Paulo. Disponível em: <http://www.livrosgratis.com.br/ ler-livro-online-136905/processo-de-tomada-dedecisao-no-ciberespaco--o-papel-das-redessociais-no-jogo-das-escolhas-individuais> Acesso em: 26 abr. 2018.

MANHÃES, E. Análise do discurso. In: DUARTE, J.; BARROS, A.; NOVELLI, A. L. R. (Orgs.). Métodos e técnicas de pesquisa em Comunicação. 2. ed. São Paulo: Atlas, 2009.

MONTEIRO, C. S. Fundamentos para uma teoria da decisão judicial. In: CONGRESSO NACIONAL, Belo Horizonte: Anais PUC/MG, 2007. p.6104$6125 . \quad$ Disponível em: <http://www.publicadireito.com.br/conpedi/man aus/arquivos/anais/bh/claudia_servilha_ monteiro.pdf>. Acesso em: 10 jan. 2018. 
NOJIRI, S. Decisão judicial. In: CAMPILONGO C. F.; GONZAGA, A. A.; FREIRE, A. (coords.). Enciclopédia jurídica da PUC-SP:Tomo: Teoria Geral e Filosofia do Direito. São Paulo: Pontifícia Universidade Católica de São Paulo, 2017. Disponível em: <https://enciclopediajuridica.pucsp.br/verbete/5 7/edicao-1/decisao-judicial>. Acesso em: 09 jan. 2018.

PAGANELLI, C. J. M; SIMÕES, A. G. A busca da verdade para produção de provas no direito digital. Âmbito Jurídico, Rio Grande, v.15, n.103, ago., 2012. Disponível em: <http://www.ambitojuridico.com.br/site/?n_link=revista_artigos_leitu ra\&artigo_id=11800>. Acesso em: 07 jan. 2018.

RECUERO, R. Redes sociais na internet. Porto Alegre: Sulina, 2009.

TOMAÉL, M. I.; ALCARÁ, A. R.; CHIARA, I. G. D. Das redes sociais à inovação. Ci. Inf., Brasília, v. 34, n. 2, p. 93-104, maio/ago. 2005. Disponível em:

<http://www.scielo.br/pdf/ci/v34n2/28559.pdf> Acesso em: 26 abr. 2018.

TOMAÉL, M. I.; MARTELETO, R. M. Redes sociais: posições dos atores no fluxo da informação. Encontros Bibli, Universidade Federal de Santa Catarina Florianópolis, Brasil, n. 1, p. 75-91, 2006. Disponível em: <https://periodicos.ufsc.br/index.php/eb/article/ view/1518-2924.2006v11nesp1p75/387> Acesso em: 26 abr. 2018.

VIANNA, J.; KANIAK, T. "PF prende uma pessoa em operação contra racismo, ameaça, incitação e terrorismo praticados na internet". Disponível em: <https://g1.globo.com/pr/parana/noticia/pffaz-operacao-contra-crimes-de-racismo-ameacae-incitacao-e-terrorismo-praticados-nainternet.ghtml>. Acesso em: 15 jul. 2018.

Recebido para publicação em 03/08/2018 Aceito em 06/08/2018 